\title{
When keeping secrets may cause harm
}

\author{
Leone Ridsdale UMDS Guy's and St Thomas's Hospitals, London
}

\section{Author's abstract}

A GP is not informed that her patient is HIV-positive. The question is posed - should doctors in special clinics act on the assumption that patients do not want their GP informed? It is argued that this assumption may be false, and that it may deny patients the offer of appropriate and timely support.

Not long ago a patient came to see me. He was not born in the locality, but had lived there for several years. He shared a large flat with his partner, a senior theatre technician. As each of their mothers were widowed, the couple had brought them to live in the flat.

On this occasion my patient asked me to arrange an AIDS test. I telephoned the local hospital to ask which bottles to use, and was told that they no longer allowed GPs access to this service. If the patient wanted the test, he should go to the hospital clinic. I passed the information on to the patient and he said he would go.

For a year I heard nothing. In the absence of information, I assumed either that he had not gone, or that the test was normal. A year later the patient returned. Before seeing me he told the nursereceptionist that he was HIV-positive. He wanted this recorded so that anyone who took blood from him in the practice would know in advance.

He told me that he had been to the hospital. After the test, the doctor informed him that he had 'drawn the black straw'. He had not appreciated the mixed metaphor. But he added that he realised that when the message was bad, there was a tendency to blame the messenger. He had not gone back to the hospital.

During the ensuing year he had developed a spot and watched it, worrying if this was the beginning of AIDS. When colds lasted longer than usual, he again worried that it might be the beginning of the end. He said his partner had been understanding and caring. His partner had expressed tenderness and continuing desire. We discussed safe sex, but my patient said he had had no desire for sexual relations and had avoided sex since he had been given his diagnosis.

\section{Key words}

AIDS; AIDS-confidentiality.
During the preceding few months, his mother, at his suggestion, had gone for a long visit to his sister who lived abroad. I had wondered, at the time, if he was being less caring towards her. He put this in context, explaining that he had not told his mother of his condition. The reason he proposed that she might try living with his sister was that he might not be able to care for her in the future. He subsequently told his mother the diagnosis.

Six months later the patient returned with herpes zoster. We thought this might be the beginning of Aids-Related-Complex, and he asked to be referred to another hospital.

We have discussed whether his partner should be tested for HIV. His partner works in operating theatres and might be accidentally injured during a surgical invasive procedure. There may be some risk to others, though with normal precautions this would be very small. He has not come for a test and his HIV status is unknown.

A principle which has affected care in this case has been confidentiality. Previously I practised in Montreal where there were no VD clinics. Patients came to their GP with sexually transmitted disease. Consultants might have difficult cases referred to them but there was no rule by which consultants would generally keep information in confidence from general practitioners. In Britain, by contrast, confidentiality within genito-urinary medicine clinics is strictly maintained, so that even GPs are often not informed of their patients' visits, diagnoses or management.

Information which is kept in confidence from general practitioners might result in acts or omissions which, if they had full information, would be contrary to good practice. For example, I have inserted an IUCD in a woman not knowing she had previously had pelvic inflammatory disease. In the case of the man told he was HIV-positive, I did not provide counselling and support at a time when it might have been useful.

I believe venereal disease clinics should at least not assume that patients do not want their GP to know about their problem and its hospital management. This is particularly so when patients are referred because GPs lack access to particular laboratory tests. Patients' interests might be better served by asking them, in all cases, if they wish information about them to be sent to 
their general practitioner.

A second issue in this case also relates to the question: 'To what extent should confidentiality take precedence over other principles?' The hospital doctors and ourselves have respected the privacy of this patient's partner and his right not to know his HIV status. This judgement involves difficult-to-defineand-measure estimates of risk and benefit. At the moment this lack of knowing may do more good than harm for this particular family. But to what extent should we be concerned with the possibility of risk to others, even if small?

Post-script. The theatre-technician partner has now gone to the clinic and been tested. He is HIV-positive.

Leone Ridsdale BA MSc MD is a Senior Lecturer in
General Practice, UMDS Guy's and St Thomas's Hospitals, London.

\section{Editor's note: At the coalface}

At the coalface is an intermittent series in which readers relate an ethical dilemma they have experienced themselves in the course of their work, with as much or as little analysis as they wish. The journal is keen to publish such reports and any reader wishing to contribute should send his or her paper (500-3500 words) to the Editor, Journal of Medical Ethics, clo Imperial College of Science, Technology and Medicine, 14 Prince's Gardens, London SW7 1NA. Contributions can be published anonymously if the writer wishes. 